to the committee, British leadership in many areas of the field is steadily diminishing as workers in the United States and other countries take the initiative. The working group has reached the dismal conclusion that "we cannot sustain a desirable momentum in this country, or exploit the possibilities of advance which we clearly see ahead, unless we find ways of substantially increasing the numbers of first class biologists at the molecular level above the 50 to 100 we have today".

In an attempt to find out how many molecular biologists there are in Britain - and anyone with pretensions to being a biochemist, a cell biologist or molecular geneticist was included in that category-the working group surveyed the output of scientific papers in fifteen journals between. July 1964 and June 1966. The British output was about 500 papers and much of this work "is at best dull and at worst trivial" from 1,800 scientists. Altogether, this accounts for 12 per cent of the total population of biologists in Britain, and the working group considers this too small a proportion. Worse still, most of these are people working in virtual isolation or in groups which under existing conditions will never reach a critical mass.

The report criticizes the slowness with which undergraduate and post-graduate teaching programmes have been adapted to the new attitudes in biology which is, of course, a consequence of the small number of posts offering reasonable career prospects and research facilities for molecular biologists. There is no overall shortage of jobs for biologists but too many of the posts and too much of the available money support activities which "are by any reckoning quite out of date". "Inbreeding", the widespread tendency of universities to hang on to their best students and eventually recruit them as staff, and tenure obtained too early and too easily, contribute to this. And the failure to provide post-doctoral fellowships with decent salarics and research facilities encourages British postdoctoral fellows in the United States to remain. The

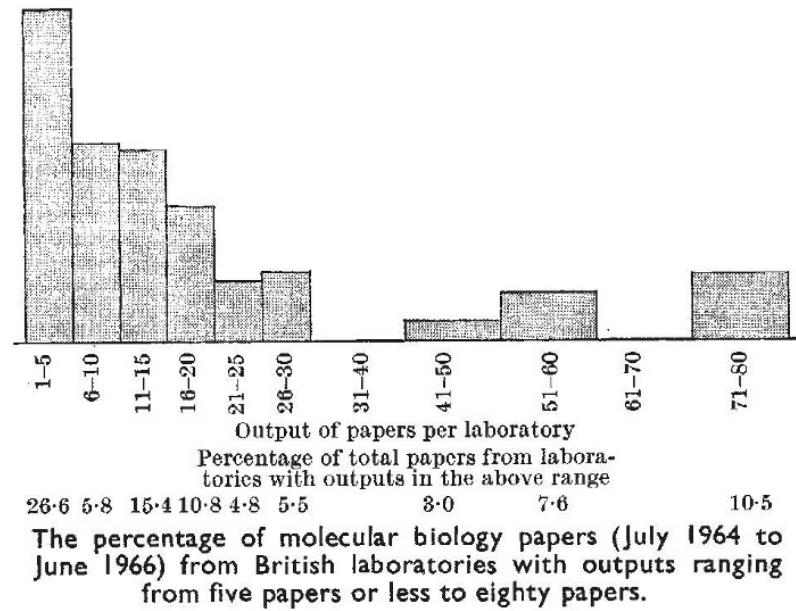

report sees no stopping the brain drain "unless conditions in Britain are greatly improved. One might seriously ask whether any other factor except sentiment prevents a wholesale emigration of the better workers". With the slim chance that the recommendations will be implemented in the near future, that is probably sound advice.

The working group also calls for a relaxation of the traditional departmental boundaries so that undergraduates receive a unified course in biology. At the post-graduate level, it advocates a preliminary year of course work on the American model before embarking on full time research. At the post-doctoral level, it asks for the provision of fellowships, again on the American model, to cover the years between the $\mathrm{PhD}$ degree and a university post. A prerequisite of further advance, however, is the establishment of what the report calls "focal centres", and what other people call centres of excellence. The report suggests that six or seven are needed which could include "the two or three in existence". But which laboratories are these? The report coyly refrains from naming any laboratory or centre but inevitably "existing centres" must mean the MRC laboratory at Cambridge and perhaps the National Institute of Medical Research at Mill Hill. The working group envisages these "focal centres" as part of universities, complementary to the science departments of the parent universities and providing research facilities for staff and post-doctoral fellows, and post-graduate training. On the American pattern, tenured associate professorships should be made available to outstanding younger men and the "focal centres" should be prepared to spend about $£ 2,500$ annually to provide facilities for each research worker.

It calls on the UGC, the research councils and the universities to put their heads together, declare their interest and make specific proposals in effect to bid for the centres. The report is now in the hands of the Department of Education and Science awaiting implementation.

\section{Computers Not On Tap}

Changes in the constitution of the Computer Board were predicted by its chairman, Professor B. H. Flowers, when he opened recently a hybrid computer facility at the Department of Engineering at Cambridge. Professor Flowers explained that there are two areas in which the board is unable to help the universities because its constitution specifically limits it to digital machines. For this reason, the board was unable to supply analogue machines or machines for teaching. The need for analogue or hybrid systems was not yet entirely clear, but Professor Flowers said that at a later stage it might seem sensible to extend the board's powers. On teaching, Professor Flowers said that the board had decided that there was need for a full study of computer teaching requirements as a separate issue and the UGC had agreed. A joint working party was being appointed to investigate the matter, and it was possible that the board's power would be extended to include teaching.

Professor Flowers also took the opportunity of explaining Science Research Council policy towards the support of science. Within each area of science, he said, there would be an increasing tendency to concentrate resources on schemes "most likely to yield substantial scientific advance or to be the basis of economic or social benefit". Already several subjects had been selected; these were control engineering, computer science, plasma physics, applied mathematics, astronomy, neutron beam techniques in biology, chemistry, metallurgy and physies, enzyme chemistry, industrial biology and polymer and material science. In all these areas, he said, the SRC was aiming for greater concentration of support in a more limited 
number of institutions. Control engineering, for example, would be supported principally in Cambridge, Imperial College and the University of Manchester Institute of Science and Technology. There would in addition be a number of second-tier departments in which specialized lines of research could go on, but the SRC could not support any other department on the scale of the top three unless its programme "turned out to be of outstanding brilliance and industrial importance, and unless arrangements for collaboration and sharing of expensive equipment have been made". Meanwhile, he suggested that the favoured centres should remember that they have a special responsibility to less well supported departments.

\section{Sciences in Parliament}

THIs week the scientific section of the House of Commons Library celebrated its second anniversary, and it is more than a little sobering to realize that the section is such a recent innovation. It seems also to be still possible for the needs of some 630 members to be served by a scientific section of two within the larger research section of the library. Dr John Poole is in charge of the scientific section and is assisted by Dr Diana Holden. So far they seem not to be grossly overworked, but it is clear that if the growth of enquiries continues at present rates, the staff will have to be increased. At present, the section deals with about 400 enquiries a year, although there are only a few members-perhaps no more than twenty-who take an intelligent interest in science.

The work of the Select Committee on Science and Technology and the Select Committee on Agriculture has clearly acted as a great stimulus to the library. In this sense, though the staff of the library would be far too polite to say so publicly, the scientific section could help to repair the deficiencies in the machinery of the House of Commons described two weeks ago by the clerk of the house, Sir Barnett Cocks. Sir Barnett criticized the Treasury sharply for not allowing the house to increase the number of clerks from thirty-six to forty-six. The clerks are now very seriously overworked, and new ones are hard to recruit. The library staff naturally occupies a rather different position from the clerks, but its members have been sitting in on sessions of the select committees, analysing documents and providing information. Library staff try to adopt an unbiased position, and leave the political interpretation of the information they provide to the whim of the individual member. Thus they provide all information short of actual advice - a position they apparently find neither difficult nor frustrating. Actually, there is probably less scope for work of this sort during the present select committee investigation into defence research, as there is far less documentation available for analysis. The sub-committee investigating coastal pollution, on the other hand, is overburdened with documentation and would be wise to take full advantage of help from the library staff. Without it, there is a distinct danger that all the literature gathered together simply languishes in boxes.

\section{Veterinarian Vaccinators}

The British Veterinary Association, which only four months ago maintained that vaccination against foot and mouth disease was a policy of despair, has in the aftermath of the 1967 epidemic changed its mind. It has now become convinced that vaccination is the only way to prevent epidemics of the disease. In its evidence to the Northumberland Committee, the association says that "if, for political reasons, carcase meat is still to be imported from infected countries, the only way to ensure that epidemics do not occur is to supplement the present measures with a well organised programme of systematic vaccination". The association considers that imported infected meat is the major source of infection, and it believes that the risk of airborne infection is steadily diminishing because of better control of the disease on the continent. Increased international trade and travel is tending to make the world a single ecological unit, but it is impossible to judge how serious this risk is, although it is certainly less than that from tainted meat. Only one outbreak of foot and mouth disease, in Canada in 1951, has been traced to a human carrier.

If meat imports from South America are to continue, the association now firmly believes that vaccination should be used as an adjunct, not an alternative, to slaughter. In its evidence, the association discounted the arguments against vaccination in the Gowers report. Modern vaccines give better and longer protection and, as French experience shows, it is possible to prevent epidemics even though calves and sheep are unprotected. Moreover, vaccines which are effective for pigs are expected to be available soon. The association estimates that the cost of vaccinating all cattle and sheep in Britain would be $£ 3$ million a year, which is probably less than the average real cost of the slaughter policy even in good years.

Under the association's scheme, all adult cattle would be vaccinated once a year and calves would be vaccinated twice within a three month interval once they had reached four months. Lowland sheep and pedigree pig herds would also be vaccinated, but hill sheep and other pigs might be left unvaccinated. Keeping unvaccinated pigs on the same farm as large cattle herds would be prohibited. In the event of an outbreak, all stock in the infected area would be given a booster dose of monovalent vaccine against the appropriate sub-type of the virus.

The association believes that several factors contributed to the breakdown of control in the recent epidemic. It claims that methods of livestock production have changed more in the fourteen years since the Gowers report than in any previous century. Larger herds, increased movement of cattle and new farming methods, all help the spread of the disease. The association draws the obvious parallel between foot and mouth disease and Newcastle disease or fowl pest, which, with the increased sophistication of the poultry industry, could not be controlled by slaughter, with the result that vaccination had to be introduced in 1962. The association accepts the meteorological evidence that wind and rain were important factors in the spread of the epidemic (see page 121); it suggests that danger of windborne spread could be minimized if slaughter immediately followed prompt reporting of the disease instead of being delayed, sometimes for two to three days, while the cattle are valued. Why not base this valuation on the corpse of an animal?

The association also proposes that control measures need to be tightened and an advisory board established, 